\title{
Copper protection with sodium salts of lower dicarboxylic acids in neutral aqueous solution ${ }^{1}$
}

\author{
M.O. Agafonkina, I.A. Kuznetsov, * N.P. Andreeva and Yu.I. Kuznetsov \\ A.N. Frumkin Institute of Physical Chemistry and Electrochemistry, Russian Academy of \\ Sciences, Leninsky pr. 31, 119071 Moscow, Russian Federation \\ *E-mail: anarenen@gmail.com
}

\begin{abstract}
The adsorption of sodium salts of malonic, ethylmalonic and succinic acids on copper in neutral buffer solutions with $\mathrm{pH} 7.40$ and the inhibition of copper corrosion in an aqueous solution containing $0.01 \mathrm{M} \mathrm{NaCl}$ by these compounds were studied. It was shown that the highest free adsorption energy $\left(\Delta G_{\mathrm{a}, \max }^{0}\right)$ on pre-oxidized copper $(E=0.0 \mathrm{~V})$ in borate buffer is shown by succinate anions, while that on oxide-free surface $(E=-0.60 \mathrm{~V})$ is shown by ethylmalonate anions. The $\Delta G_{\mathrm{a}, \max }^{0}$ values on oxidized copper for sodium malonate, ethylmalonate and succinate are $47.7 ; 69.4$ and $77.4 \mathrm{~kJ} / \mathrm{mol}$, respectively. Based on these values, one can assume that they are chemisorbed. Since a plateau is established on all isotherms at certain anion concentrations, it was regarded as a monolayer adsorbate coating, and the thickness of the respective monolayer was calculated from these data. Comparing this thickness with the size of the inhibitor molecules, we concluded that the anions have a planar orientation on the oxidized copper surface. On reduced copper surface, the $\Delta G_{\mathrm{a}, \max }^{0}$ values are noticeably smaller i.e., 38.3; 64.2 and $53.1 \mathrm{~kJ} / \mathrm{mol}$ for malonate, ethylmalonate and succinate, respectively. This indicates that at least succinate and ethylmalonate anions are chemisorbed on reduced copper surface. Copper corrosion tests in water containing $10 \mathrm{mmol} / \mathrm{L} \mathrm{NaCl}$ also showed the advantage of sodium succinate and ethylmalonate over sodium malonate. The highest degree of copper corrosion protection is provided by $3 \mathrm{mmol} / \mathrm{L}$ sodium ethylmalonate: $Z=91 \%$, while for sodium succinate and malonate it is $Z=83$ and $77 \%$, respectively.
\end{abstract}

Keywords: adsorption, sodium dicarboxylates, copper corrosion inhibitors, Temkin isotherm, adsorption energy, ellipsometry.

Received: August 3, 2020. Published: August 11, 2020

doi: $\underline{10.17675 / 2305-6894-2020-9-3-13}$

\footnotetext{
${ }^{1}$ This work was carried out with partial financial support from the Russian Foundation for Basic Research (Grant No. 20-03-00101 "Adsorption of anions of dicarboxylic acids on copper and its alloys and their passivation in neutral solutions").
} 


\section{Introduction}

Copper and its alloys exposed to a humid atmosphere or sea water can become covered with corrosion products that are referred to as patina. To protect copper from corrosion damage, organic compounds called corrosion inhibitors (hereinafter called "inhibitors" for brevity) are used [1]. When they are added to a corrosive environment where a metal is located, the surface destruction is reduced or nearly prevented. A nitrogen-containing heterocycle, 1,2,3benzotriazole $\mathrm{C}_{6} \mathrm{H}_{5} \mathrm{~N}_{3}$ (BTA) that began to be studied back in the 1960 s is often used as an inhibitor for copper [2]. It belongs to the 3rd hazard class, i.e., moderately hazardous compounds, according to GOST 12.1.007-76. In view of this, studies are underway to replace this compound with less toxic and more environmentally friendly inhibitors [3-5]. Such compounds can be salts of dicarboxylic acids found in significant amounts in some plants or are part of the cell sap, therefore, when they are used as inhibitors, it can be assumed that they do no harm to the environment [6].

The recently published review [7] describes in detail the salts of many carboxylic acids (mono-, di-, and polycarboxylates) that are inhibitors for various metals in media with a wide $\mathrm{pH}$ range. The study of dicarboxylic acid salts as inhibitors for the protection of iron and low-carbon steel in aqueous solutions was carried out as early as the early 1960s, although Stroud and Vernon [8] suggested using a 5\% solution of sodium succinate $\mathrm{NaOOCCH}_{2} \mathrm{CH}_{2} \mathrm{COONa}$ for impregnating cardboard packaging in order to prevent the atmospheric corrosion of steel. Later, Hefter et al. [9] studied the effect of mono$\left(\mathrm{C}_{n} \mathrm{H}_{2 n+1} \mathrm{COO}^{-}\right)$and dicarboxylate anions $\left({ }^{-} \mathrm{OOC}\left(\mathrm{CH}_{2}\right)_{n} \mathrm{COO}^{-}\right)$on the electrochemical behavior of copper, aluminum, and steel in aerated nearly-neutral and slightly mineralized aqueous solutions. They found that in a series of dicarboxylates, the protective effect for copper and aluminum is enhanced with an increase in the hydrocarbon chain length. On steel, short-chain dicarboxylates $\left(n_{\mathrm{C}} \leq 3\right)$ behaved as weak inhibitors, but starting from $n_{\mathrm{C}}=4$ and up to $n_{\mathrm{C}}=12$, their protective properties increased, then sharply decreased at $n_{\mathrm{C}}=14$.

Such changes in the inhibitors effectiveness are probably caused by competing reactions of adsorption and complexation on the metal surface (hydroxide/oxide), differences in hydrophobicity, and micelle formation. Short-chain dicarboxylates $\left(n_{\mathrm{C}}=1\right)$, for example, sodium malonate, was studied on low-carbon steel in $1 \mathrm{M} \mathrm{HCl}$ solution using a set of methods: gravimetric, potentiodynamic polarization, electrochemical impedance spectroscopy (EIS) and electrochemical frequency modulation (EFM) techniques. Sodium malonate at $25 \mathrm{mg} / \mathrm{L}$ provides a high protective effect in hydrochloric acid at $25^{\circ} \mathrm{C}$ (about 96\%) in potentiodynamic measurements (a 10-fold decrease in the active dissolution current of steel compared to the uninhibited solution) and $85.6 \%$ as estimated by the EIS method.

Researchers from Germany [11] studied the passivating effect of dicarboxylates, including straight-chain salts, for mild steel. They found that the adsorption ability of dicarboxylates is weak, but the protective effect can be improved by using a mixture of a dicarboxylate and a monocarboxylate. This increase in inhibition efficiency is associated with a higher adsorption capacity of monocarboxylates on oxidized steel surface than in the 
case of dicarboxylate. A studied sebacate/caprate mixture provides better steel protection than a mixture of the corresponding carboxylate with BTA.

Electrochemical methods were used in a study of the effectiveness of some dicarboxylates with $n_{\mathrm{C}}=2,4$ and 8 as inhibitors for low-carbon steel in neutral chloride solutions [12]. The results showed that these compounds are highly effective (over 85\%) and behave predominantly as anodic-type inhibitors. The suggested inhibition mechanism involves the formation of an insoluble Fe(III) compound on the metal surface after the initial oxidation of iron to $\mathrm{Fe}(\mathrm{II})$ ions.

It should be noted that the main attention among the salts of dicarboxylic acids was paid mainly to those compounds in which the length of the hydrocarbon chain between the two carboxy groups varied. This, of course, affects the hydrophobicity (hydrophilicity) of the dicarboxylate anion. However, it is more promising to consider alkyl derivatives of sodium malonate with the general formula $\mathrm{NaOOCCH}(\mathrm{R}) \mathrm{COONa}$, since in this case an increase in the length of the alkyl substituent $\mathrm{R}$ does not separate the adjacent carboxyl groups, which are essentially the reaction center of the salt anion. In this respect, the study of the adsorption of sodium malonate and ethylmalonate anions on copper from neutral aqueous solutions is of scientific and practical interest.

The aim of this work is to identify the features of the adsorption of the above compounds and its effect on the electrochemical and corrosion behavior of copper in neutral solutions. The adsorption and protective properties of sodium malonate and ethylmalonate will be compared with those of sodium succinate, in which the length of the hydrocarbon chain between two carboxyl groups is greater.

\section{Experimental}

Plates and electrodes of $\mathrm{M} 1$ copper $(99.9 \% \mathrm{Cu}$ ) were used in this work. Commercial malonic acid (CAS Number 141-82-2, Sigma Aldrich), its substituted derivative - ethylmalonic acid (CAS Number 601-75-2, Sigma Aldrich), and succinic acid (CAS Number 110-15-6, Sigma Aldrich) were used (Figure 1).

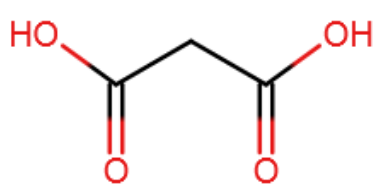

a

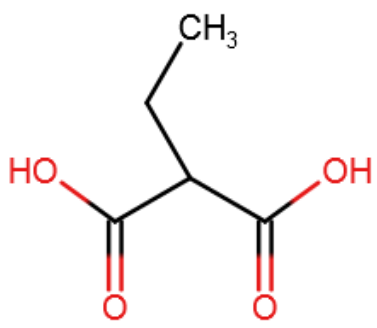

b

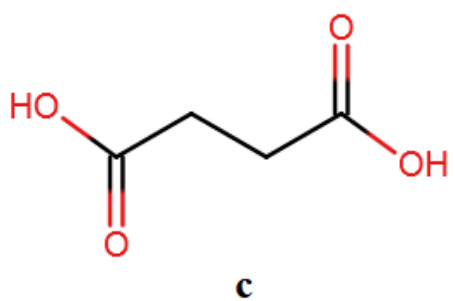

c

Figure 1. Structural formula of malonic (a), ethylmalonic (b) and succinic acids (c).

All the acids were converted to sodium salts by neutralization with a sodium hydroxide solution. The $\mathrm{pH}$ of working solutions was maintained within 6.20-7.40. Ellipsometric 
measurements were performed in highly diluted solutions $\left(10^{-8}-10^{-10} \mathrm{M}\right)$. For electrochemical and corrosion studies, $0.1 \mathrm{M}$ and $0.05 \mathrm{M}$ inhibitor concentrates were prepared.

The potentials $E$ of the electrode in the solution were measured relative to the silver chloride reference electrode; their values are given versus the standard hydrogen electrode.

Ellipsometric studies were carried out using a Rudolph Research 2000 manual ellipsometer in an electrochemical cell that simultaneously allows one to maintain a constant potential $E$ on the electrode and measure the ellipsometric angle of phase shift $\Delta$. The angle measurement accuracy was $\pm 0.05^{\circ}$. Measurements were made on electrodes with reduced $(E=-0.60 \mathrm{~V}, \mathrm{SHE})$ and oxidized surfaces $(E=0.0 \mathrm{~V}, \mathrm{SHE})$. At a thickness of homogeneous film $d \leq 10 \mathrm{~nm}$, the Drude equation is valid, which allows for a transition from changes in $\Delta$ to surface coverage degree $\theta[13]$ :

$$
d=-\alpha \delta \Delta=-\alpha\left(\Delta-\Delta_{0}\right), \theta=\beta\left(\Delta-\Delta_{0}\right),
$$

where $\alpha$ and $\beta$ is the coefficient of proportionality, $\Delta_{0}$ is the angle value for the initial surface, and $\Delta$ is the angle value during the experiment.

To obtain the adsorption isotherm of malonates or succinate, an inhibitor concentrate

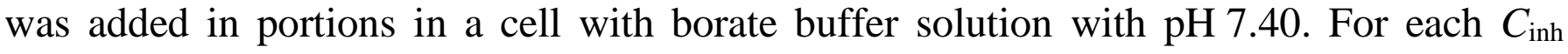
concentration, angle $\Delta$ decreases in time and after 60-90 minutes it stops changing. Thus, we define the angle difference $(-\delta \Delta)$ to build its dependence on $C_{\text {inh. }}$. The value of $C_{\text {inh }}$ at which angle $\Delta$ stops changing corresponds to the formation of a tentative monolayer. For this phenomenon, the coverage degree of the electrode surface with the adsorbate is $\theta \rightarrow 1.0$.

The experimental dependence of the angle $\Delta v s . \log C_{\mathrm{inh}}$ is converted to an adsorption isotherm $\theta=f\left(\ln C_{\mathrm{inh}}\right)$ and the free energy of adsorption $\left(-\Delta G_{\mathrm{a}, \max }^{0}\right)$ is calculated. In this case, the adsorption of malonates is adequately described in the full Temkin equation:

$$
\theta=\frac{1}{f} \ln \frac{1+B_{\max }(C)}{1+B_{\min }(C)},
$$

where $f$ is a factor of surface inhomogeneity characterizing the change in adsorption enthalpy with surface coverage; $B_{\max }$ and $B_{\min }$ are adsorption equilibrium constants corresponding to the highest and lowest energy of adsorption. The $B$ value is related to the free energy of adsorption $\left(-\Delta G_{\mathrm{a}, \max }^{0}\right)$ by the ratio:

$$
B_{\text {max }, \min }=\exp \left[\left(-\Delta G_{\mathrm{a}, \max (\min )}^{0}\right) / R T\right]
$$

In determining $\left(-\Delta G_{\mathrm{a}, \min }^{0}\right),\left(-\Delta G_{\mathrm{a}, \max }^{0}\right)$, the coefficient $f, B_{\max }$ and $B_{\min }$, the technique described previously [14] was used.

The desorption of sodium malonate was investigated as follows. Sodium malonate $(1 \mathrm{mmol} / \mathrm{L})$ was added to a cell with a pre-oxidized copper electrode at $E=0.0 \mathrm{~V}$ and kept until the angle $(-\delta \Delta)$ corresponding to a monolayer coverage changed to $\sim 0.37^{\circ} \ldots 0.40^{\circ}$. 
After that, the cell was washed with pure borate buffer and the angle $\Delta$ was this time recorded in the background solution.

Electrochemical studies involved recording anodic polarization curves in borate buffer solution with addition of $0.01 \mathrm{M} \mathrm{NaCl}$. These curves were obtained on $\mathrm{M} 1$ copper electrodes with an area of $0.78 \mathrm{~cm}^{2}$ in an electrochemical cell with separated electrode spaces using an IPC-PRO potentiostat (RF). The working electrode was successively polished on emery paper with different grit sizes (360-1000) and then degreased with acetone.

After removing the air-formed copper oxide film (keeping the electrode for $15 \mathrm{~min}$ in borate buffer $\mathrm{pH} 7.40$ with $0.01 \mathrm{M} \mathrm{NaCl}$ at $E=-0.60 \mathrm{~V}$ ), the potentiostat was turned off until the free corrosion potential $E_{\text {cor }}$ was established. After a new value of $E_{\text {cor }}$ established after the inhibitor introduced into the buffer solution adsorbed on the electrode, polarization curves were recorded at $0.2 \mathrm{mV} / \mathrm{s}$ scan rate. The local depassivation potential of copper by chlorides $\left(E_{\mathrm{ld}}\right)$ was determined from a sharp increase in the current on the polarization curve with subsequent visual identification of pits on the electrode surface. The accuracy of $E_{\mathrm{ld}}$ measurements was $0.02 \mathrm{~V}$.

Copper corrosion tests were carried out in distilled water containing $0.01 \mathrm{M} \mathrm{NaCl}$. Before the experiment, copper plates were cleaned on emery paper with various grain sizes (from 240 to 1000), degreased with acetone, and weighed. The weighing accuracy was $0.00005 \mathrm{~g}$. Then the samples were kept in a chloride solution with addition of various concentrations of sodium malonates or sodium succinate for 7 days at room temperature $t=(22 \pm 2)^{\circ} \mathrm{C}$ and with natural aeration of the solution. After the test completion, the plates were removed, cleaned from corrosion products, and re-weighed. Based on the difference in the plate masses before and after the tests, the corrosion rates in the background $\left(K_{0}\right)$ and inhibited solution $\left(K_{\text {inh }}\right)$ were calculated and the degree of copper protection $Z$ was determined by the formula:

$$
Z=\frac{K_{0}-K_{\text {inh }}}{K_{0}} \cdot 100 \%
$$

\section{Results and Discussion}

The spontaneous transition of copper in a chloride buffer solution with $\mathrm{pH} 7.40$ to the passive state upon addition of sodium dicarboxylates is directly related to the adsorption of the inhibitor on the electrode surface $[15,16]$. Such measurements were carried out using the in situ ellipsometric method at a constant electrode potential that makes it possible to take into account the different state of its surface, i.e., reduced state at $E=-0.60 \mathrm{~V}$ and oxidized state at $E=0.0 \mathrm{~V}$.

On an oxide-free copper surface at $E=-0.60 \mathrm{~V}$, the adsorption of sodium malonate $(\log D=-5.34)$ and sodium succinate $(\log D=-5.47)$ anions, despite their high hydrophilicity, occurs at very low concentrations (Figure 2). It is not surprising that the less hydrophilic anions of sodium ethylmalonate are adsorbed much better, and signs of the formation of a monolayer coverage of a reduced copper surface are observed at $C_{\text {inh }}$ below 
$10 \mathrm{nmol} / \mathrm{L}$, i.e. at concentrations 3 orders of magnitude lower than for malonate. The values of free energies of adsorption calculated from the full Temkin isotherm (Equation 2) are $38.3,53.1$ and $64.2 \mathrm{~kJ} / \mathrm{mol}$, respectively, for sodium malonate, succinate and ethylmalonate (Table 1). From this it can be concluded that the interaction of these inhibitors with reduced copper surface is of a chemisorption nature. This conclusion is most reliable in the case of the adsorption of ethylmalonate and succinate anions.

Table 1. Adsorption characteristics of isotherms for lower dicarboxylic acids on copper surface at cathodic $E=-0.60 \mathrm{~V}$ and anodic $E=0.0 \mathrm{~V}$ potentials.

\begin{tabular}{|c|c|c|c|c|c|c|}
\hline Inhibitor & $E, \mathbf{V}$ & $\begin{array}{l}B_{\mathrm{i}, \max } \\
\mathrm{L} / \mathrm{mol}\end{array}$ & $\begin{array}{l}B \text { i,min, } \\
\text { L/mol }\end{array}$ & $\begin{array}{l}\Delta G_{\mathrm{a}, \max }^{0}, \\
\mathrm{~kJ} / \mathrm{mol}\end{array}$ & $\begin{array}{l}\Delta G_{\mathrm{a}, \max }^{0}, \\
\mathrm{~kJ} / \mathrm{mol}\end{array}$ & $f$ \\
\hline \multirow{2}{*}{ Sodium malonate } & -0.60 & $9.49 \cdot 10^{4}$ & $6.85 \cdot 10^{3}$ & 31.8 & 38.3 & 2.62 \\
\hline & 0.00 & $0.43 \cdot 10^{7}$ & $0.08 \cdot 10^{7}$ & 43.6 & 47.7 & 1.65 \\
\hline \multirow{2}{*}{ Sodium ethylmalonate } & -0.60 & $3.28 \cdot 10^{9}$ & $4.9 \cdot 10^{8}$ & 59.5 & 64.2 & 1.90 \\
\hline & 0.00 & $0.28 \cdot 10^{11}$ & $0.14 \cdot 10^{11}$ & 67.6 & 69.4 & 0.70 \\
\hline \multirow{2}{*}{ Sodium succinate } & -0.60 & $3.7 \cdot 10^{7}$ & $1.17 \cdot 10^{7}$ & 50.2 & 53.1 & 1.15 \\
\hline & 0.00 & $6.72 \cdot 10^{11}$ & $1.52 \cdot 10^{11}$ & 73.7 & 77.4 & 1.49 \\
\hline
\end{tabular}

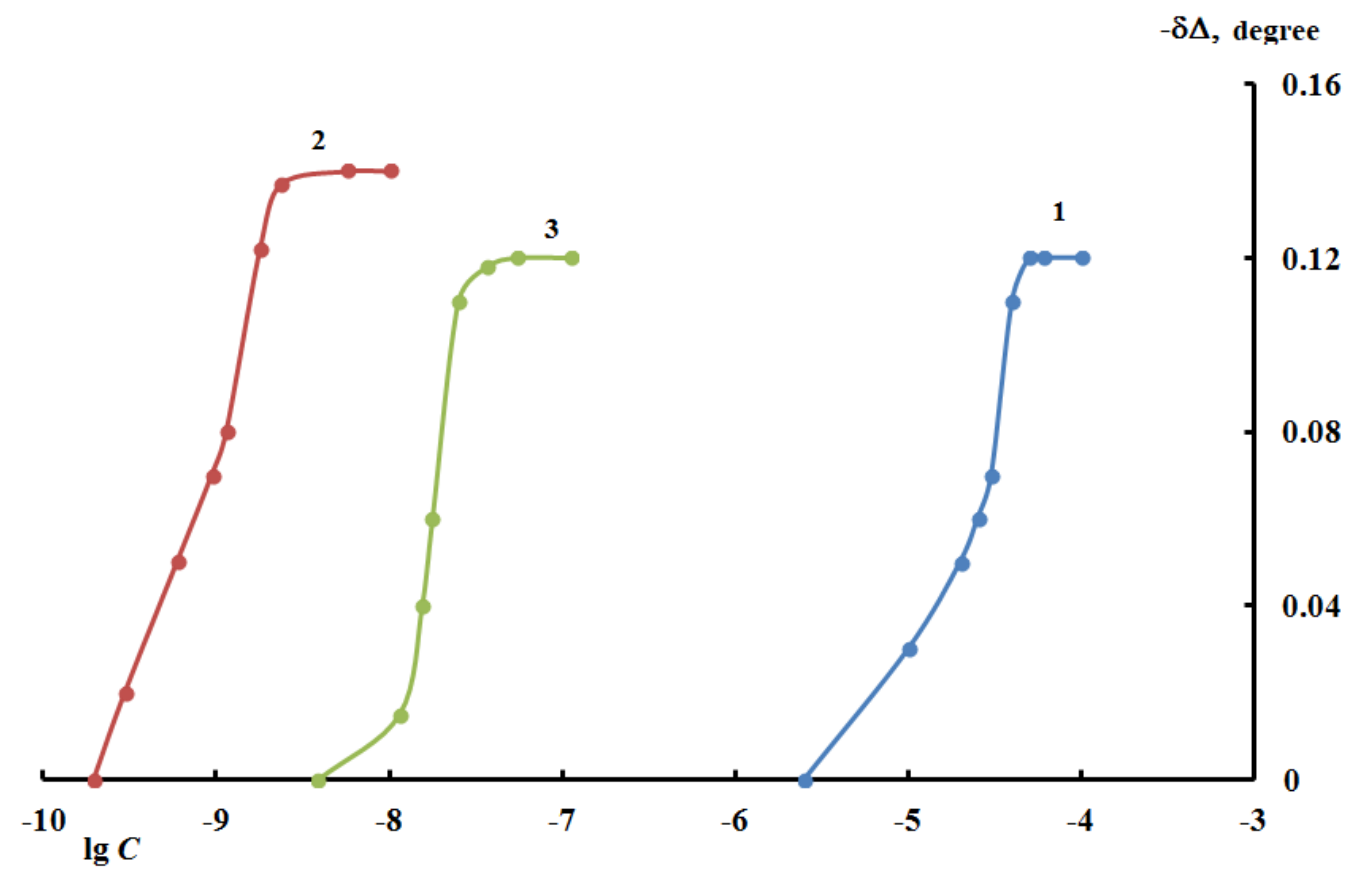

Figure 2. Dependence of $(-\delta \Delta)$ on the logarithm of inhibitor concentration: sodium malonate (1), sodium ethylmalonate (2) and sodium succinate (3) on reduced copper surface at $E=-$ $0.60 \mathrm{~V}$ in a borate buffer solution with $\mathrm{pH} 7.40$. 
From the changes in the ellipsometric angle $\Delta$ versus the concentration of dicarboxylates (Figure 2), it is possible to determine the thickness of a tentative monolayer of each compound. For the reduced surface $\alpha=0.89 \mathrm{~nm} / \mathrm{deg}$; the corresponding thicknesses are given in Table 2. These thicknesses are compared with the molecular length of the dicarboxylic salt. For all three salts on reduced copper, the thickness $d$ is less than the molecule length, which indicates a planar arrangement of the anion in the layer.

Table 2. Thickness of a tentative monolayer on reduced and oxidized copper surface in a neutral borate buffer solution $\mathrm{pH} 7.40$ for the studied dicarboxylates according to ellipsometric data.

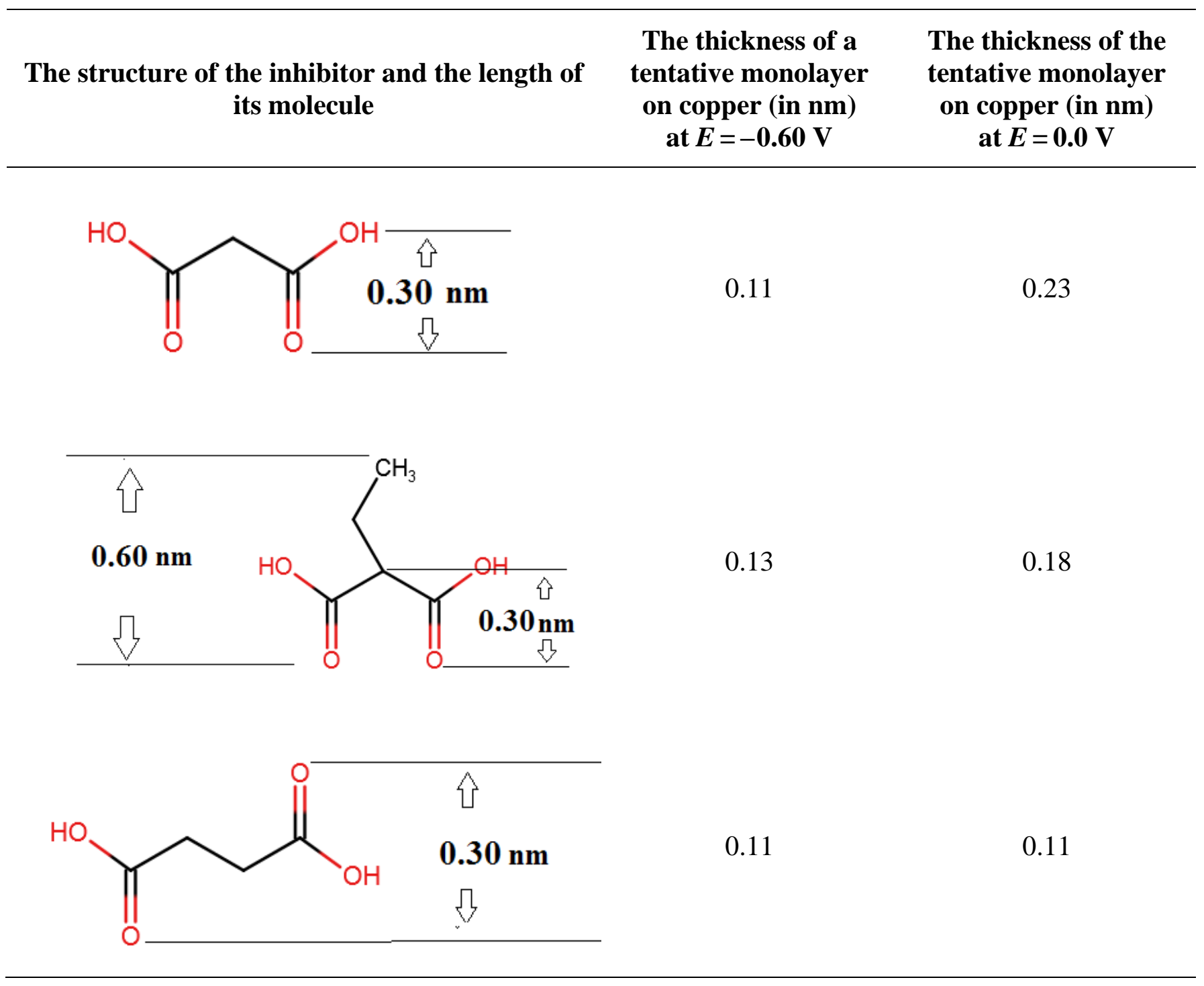

Previously, we studied the adsorption of oleylsarcosinate and sodium oleate on reduced copper surface at $E=-0.60 \mathrm{~V}$ [17]. Calculation of the free energy of adsorption by the full Temkin equation showed that the adsorption of sodium oleate is a physical process $\left(\Delta G_{\mathrm{a}, \max }^{0}=\right.$ $39.6 \mathrm{~kJ} / \mathrm{mol})$ and that of sodium oleylsarcosinate is chemisorption $\left(\Delta G_{\mathrm{a}, \max }^{0}=54.8 \mathrm{~kJ} / \mathrm{mol}\right)$. 
Comparison of the adsorption of mono- and dicarboxylate salts on oxide-free copper surface from borate buffer shows that hydrophilic sodium malonate and sodium succinate are close in $\Delta G_{\mathrm{a} \text {,max }}^{0}$ values to hydrophobic sodium oleate (Table 3), while sodium ethylmalonate exceeds sodium oleylsarcosinate by $10 \mathrm{~kJ} / \mathrm{mol}$, despite its clearly lower hydrophobicity. From these facts it can be assumed that the dicarboxylate anions form stronger bonds with copper than monocarboxylate anions due to the presence of two spatially close carboxyl groups in the former.

Table 3. Physicochemical characteristics of the compounds: acid dissociation constants $\mathrm{p} K_{\mathrm{a}}$, logarithm of distribution coefficients $(\log P)$. The $\mathrm{p} K_{\mathrm{a}}, \log D$ and $\log P$ values were obtained using the chemicalize.com resource.

\begin{tabular}{cccc}
\hline Inhibitor & $\log \boldsymbol{P}$ & $\log \boldsymbol{p} \boldsymbol{K}_{\mathbf{a}}$ \\
\hline Malonic acid & -0.33 & -5.34 & 2.43 \\
& & & 5.92 \\
Ethylmalonic acid & 0.66 & -3.73 & 2.50 \\
& & & 6.58 \\
Succinic acid & -0.40 & -5.47 & 3.55 \\
Oleic acid & 7.70 & 5.10 & 5.69 \\
$N$-Oleylsarcosine & 7.00 & 5.65 & 4.80 \\
\hline
\end{tabular}

In [15], the adsorption of sodium malonate on oxidized copper was studied and it was shown that it begins in the region of $C_{\text {inh }} \geq 0.12 \mu \mathrm{mol} / \mathrm{L}$, while at $5 \mu \mathrm{mol} / \mathrm{L}$, a monolayer surface coverage is already observed. In comparison with the reduced surface, the maximum coverage of oxidized copper surface with sodium malonate is reached earlier, i.e. at much lower concentrations. In the present work, it was found that ethylmalonate is adsorbed already at almost more than 4 orders lower $C_{\text {inh }}$ (Figure 3). The $\Delta G_{\mathrm{a}, \max }^{0}$ values of malonate and ethylmalonate anions on oxidized copper calculated from Equation 2 are 47.7 and $69.4 \mathrm{~kJ} / \mathrm{mol}$, respectively. Sodium succinate is adsorbed on oxidized copper at $C_{\text {inh }}=0.005 \mathrm{nmol} / \mathrm{L}$, which is 3 orders of magnitude lower than for sodium malonate. The value of $\left(\Delta G_{\mathrm{a}, \max }^{0}\right)$ is $77.4 \mathrm{~kJ} / \mathrm{mol}$ in this case (Table 1). This value is 8 and $30 \mathrm{~kJ} / \mathrm{mol}$ higher than for sodium ethylmalonate and sodium malonate, respectively.

The plots of changes in ellipsometric angles on the concentration of sodium dicarboxylates (Figure 3) allow us to estimate the thicknesses of monolayers of the studied inhibitor anions on oxidized copper. From Equation 1, using the coefficient $\alpha=$ $0.53 \mathrm{~nm} / \mathrm{deg}$, one can calculate the thickness of a tentative monolayer of dicarboxylates on oxidized surface. The thickness of a tentative monolayer of malonate is $0.23 \mathrm{~nm}$, that of ethylmalonate is $0.18 \mathrm{~nm}$, and that of succinate is $0.11 \mathrm{~nm}$. Comparing these values with the 
sizes of molecules, one can assume their almost planar arrangement on oxidized surface, like on oxide-free surface (Table 2).

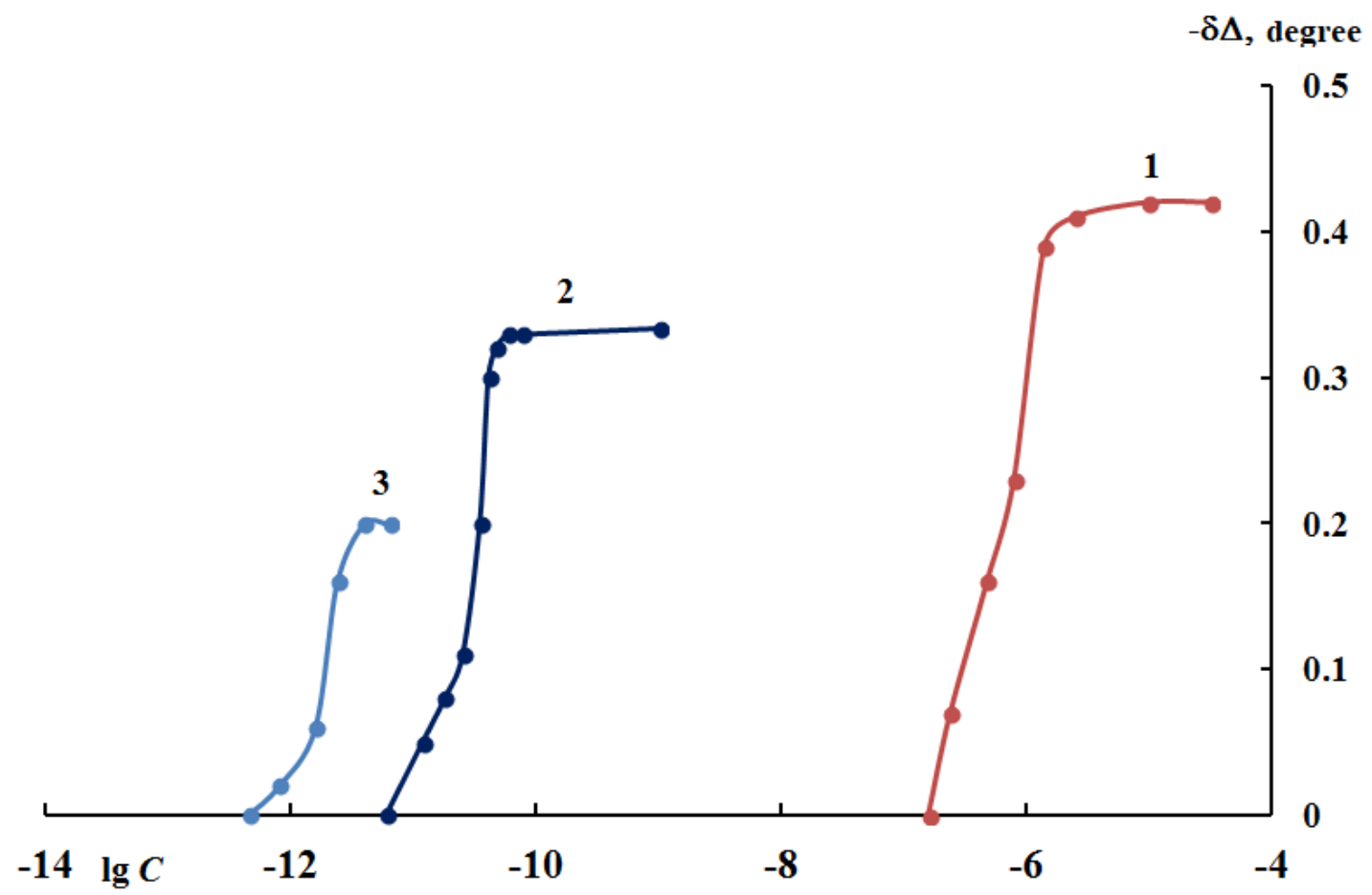

Figure 3. Dependence of $(-\delta \Delta)$ on the logarithm of inhibitor concentration: sodium malonate (1), sodium ethylmalonate (2) and sodium succinate (3) on oxidized copper surface at $E=0.0 \mathrm{~V}$ in borate buffer solution with $\mathrm{pH} 7.40$.

The high $\Delta G_{\mathrm{a}, \max }^{0}$ values for the three studied salts of dicarboxylic acids are evidence in favor of their chemisorption. This is also indicated by the results of studying the desorption of the anion characterized by the smallest $\Delta G_{\mathrm{a}, \max }^{0}$ value, i.e. malonate studied by us earlier in [15], from oxidized copper surface. It was shown that after replacement of the solution, a further decrease in $\Delta$ occurred, i.e., an increase in $(-\delta \Delta)$, no desorption. Within 120 minutes the angle decreased, which is in favor of chemisorption of the malonate anion on the electrode (Figure 4).

Polarization measurements on copper in a buffer solution with $\mathrm{pH} 7.40$ in the presence of the dicarboxylates under study were carried out with addition of corrosive sodium chloride $(10 \mathrm{mmol} / \mathrm{L})$. The data obtained at the same concentration $(3 \mathrm{mmol} / \mathrm{L})$ are shown in Figure 5. Malonate and ethylmalonate shift the pitting potential with respect to the background ( 0.09 and $0.10 \mathrm{~V}$, respectively) by approximately the same amount. In the case of sodium succinate, local depassivation of the electrode begins at $0.71 \mathrm{~V}$, which is $0.15 \mathrm{~V}$ higher than in the background solution. This indicates that copper is better protected with sodium succinate. All the carboxylates studied decrease the current density of copper anodic dissolution from $60 \mu \mathrm{A} / \mathrm{cm}^{2}$ to $15 \mu \mathrm{A} / \mathrm{cm}^{2}$. 


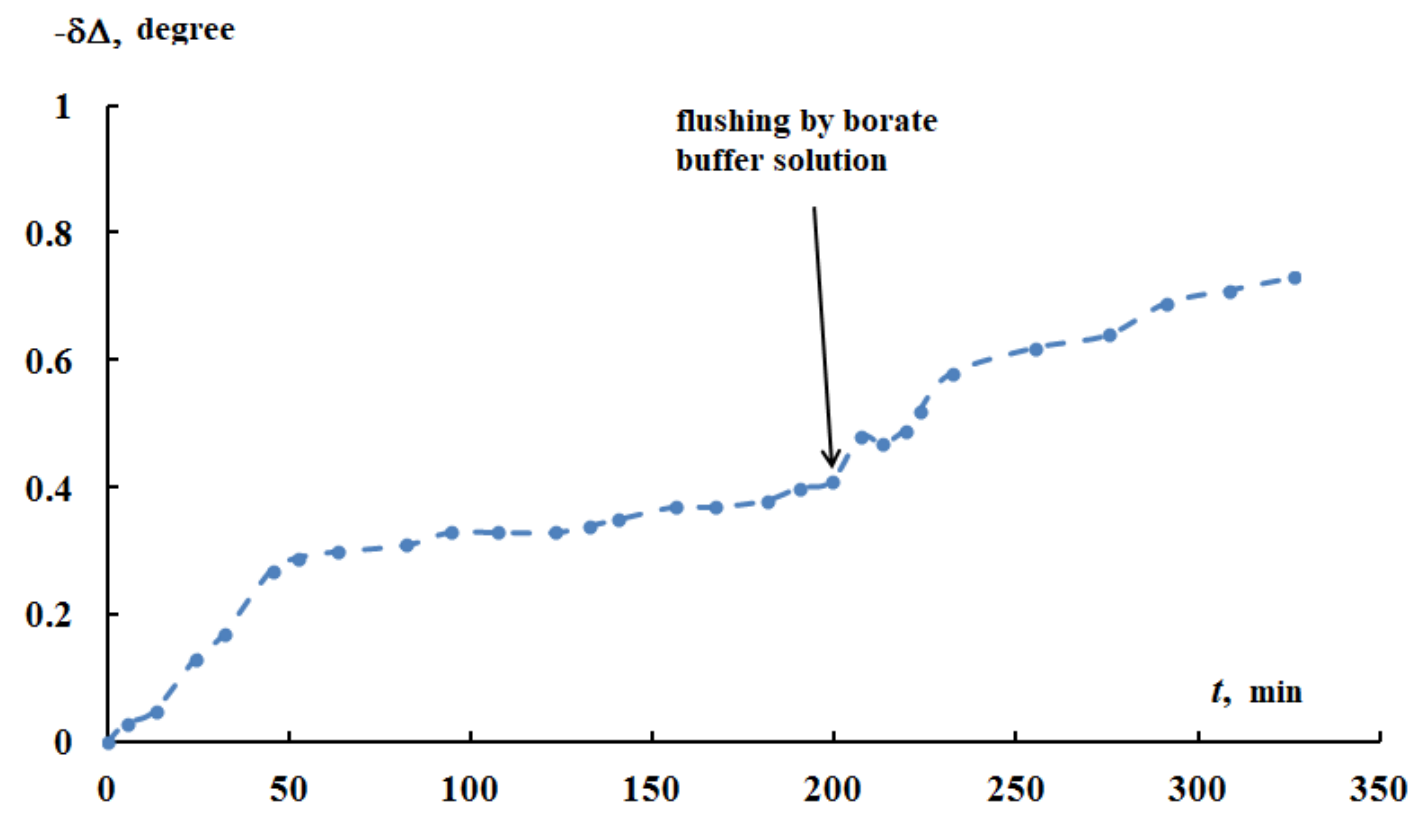

Figure 4. Desorption of $1 \mathrm{mmol} / \mathrm{L}$ sodium malonate from an oxidized copper surface at $E=0.0 \mathrm{~V}$ from a neutral borate buffer with $\mathrm{pH} 7.40$. The arrow indicates the process of flushing the cell with a pure buffer solution with $\mathrm{pH}$ 7.40.

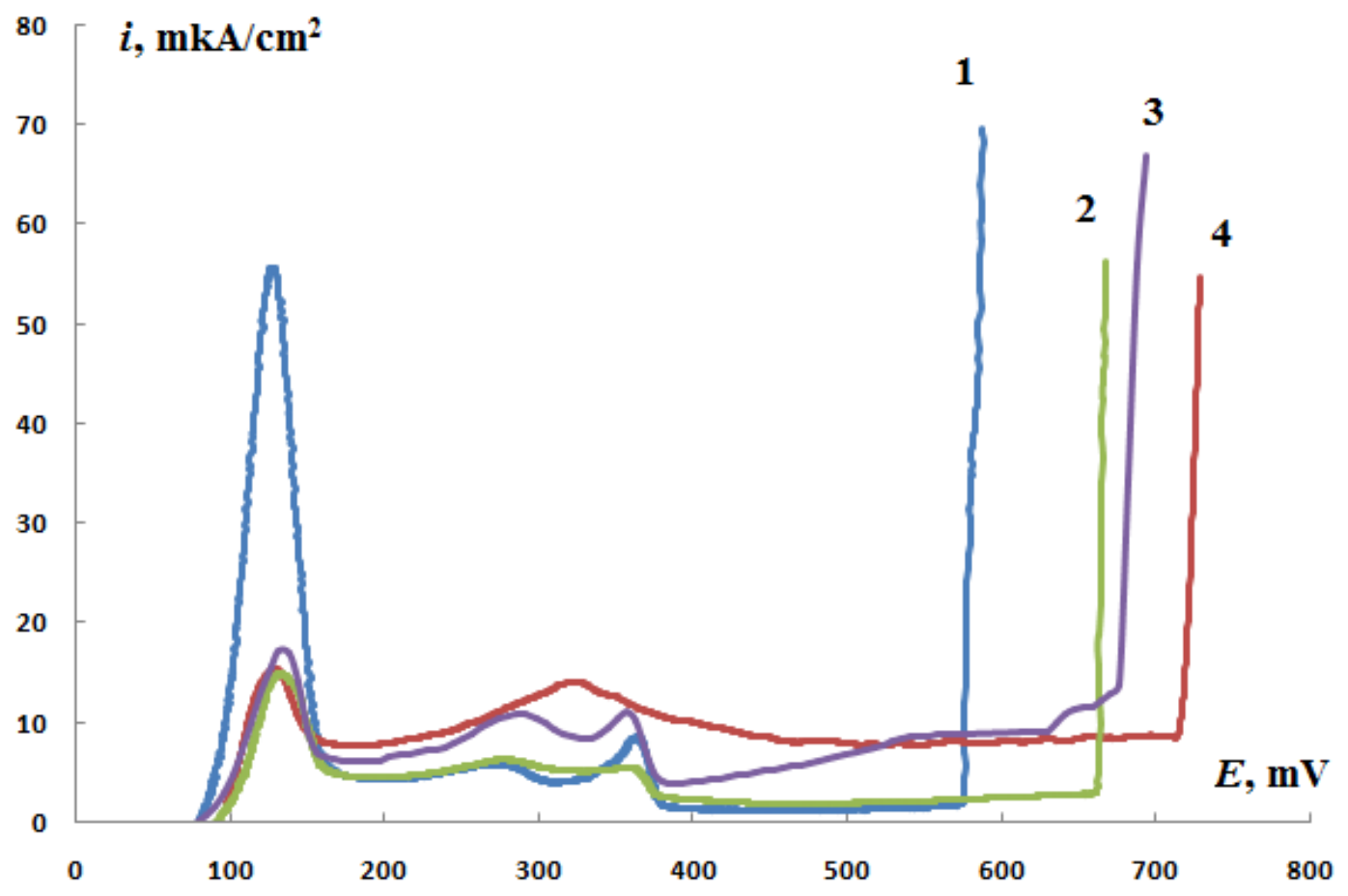

Figure 5. Copper anodic polarization curves in a borate buffer solution with $\mathrm{pH} 7.40$ containing $10 \mathrm{mmol} / \mathrm{L} \mathrm{NaCl}$ with addition of $3 \mathrm{mmol}$ inhibitors: 1 - background, 2 - sodium malonate, 3 - sodium ethylmalonate, 4 - sodium succinate. 
Thus, the results of electrochemical and ellipsometric studies show that sodium ethylmalonate and succinate are superior to sodium malonate in the inhibition of the copper anodic dissolution in a neutral buffer solution with $\mathrm{pH}$ 7.40. This is consistent with the enhanced adsorption activity of ethylmalonate anions or an increase in the number of $\mathrm{CH}_{2}$ units in the structure of succinic acid in comparison with unsubstituted acid.

In this regard, it is of interest to evaluate the protective ability of sodium salts of three dicarboxylic acids with respect to copper in an aqueous chloride solution. Figure 6 shows the results of 7-day corrosion tests in $0.01 \mathrm{M} \mathrm{NaCl}$ aqueous solution. Starting with $C_{\text {inh }}=0.2 \mathrm{mmol} / \mathrm{L}$, sodium ethylmalonate is superior to sodium malonate in copper corrosion inhibition but slightly inferior to sodium succinate. At $C_{\mathrm{inh}}=1.5 \mathrm{mmol} / \mathrm{L}$, malonate, ethylmalonate and sodium succinate provide $Z=65,71$ and $73 \%$, respectively.

With an increase in $C_{\text {inh }}$ to $2.5 \mathrm{mmol} / \mathrm{L}$, the advantage of sodium succinate over malonate and its derivatives is preserved $(Z=76,77$ and $83 \%$, respectively), but at $C_{\text {inh }}=3.0 \mathrm{mmol} / \mathrm{L}$, the protective effect of malonate and succinate ceases to grow, whereas sodium ethylmalonate provides $Z=91 \%$.

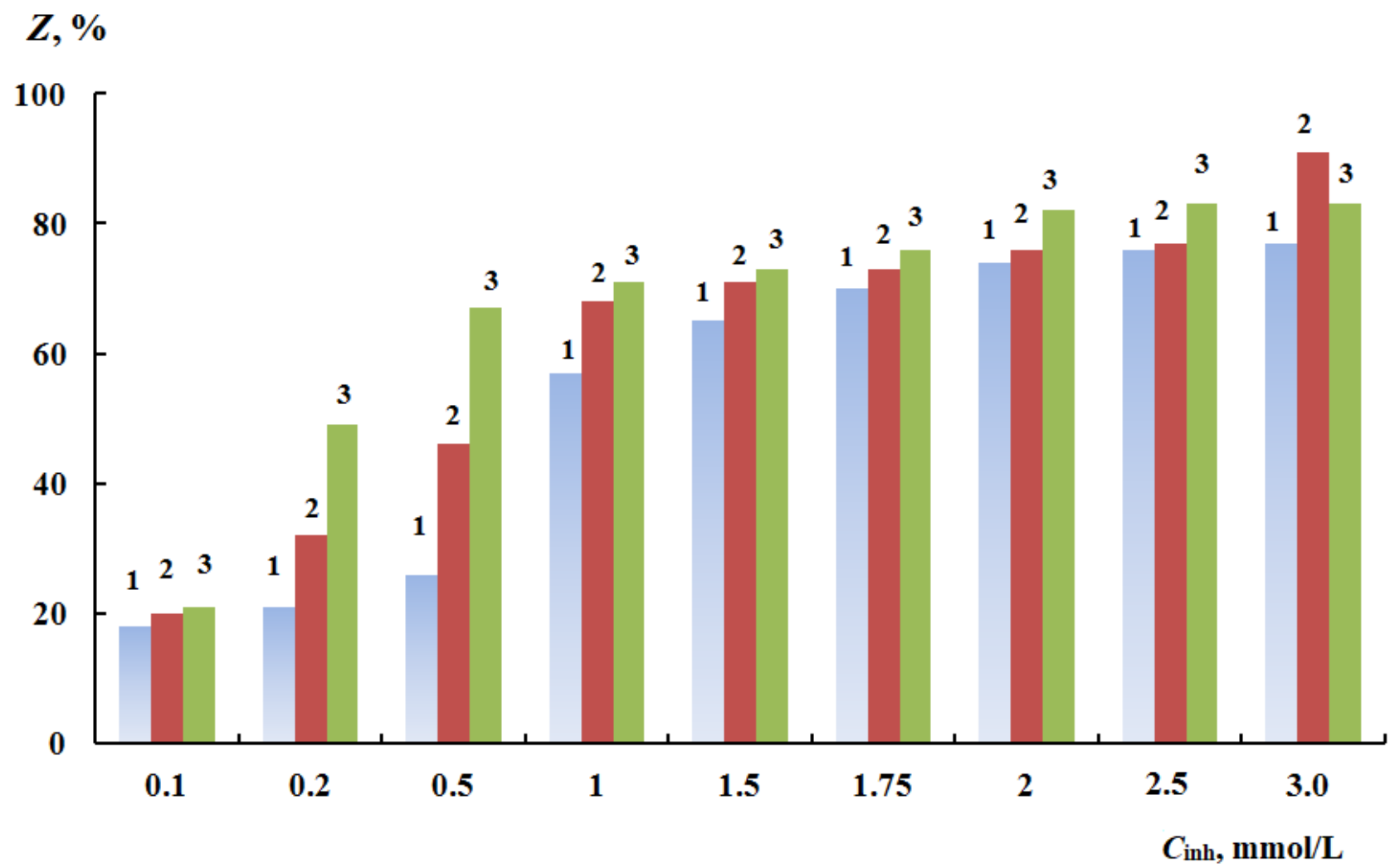

Figure 6. Dependence of the protection degree $Z(\%)$ on the concentration of the inhibitors (in $\mathrm{mmol} / \mathrm{L}$ ): 1 - sodium malonate, 2 - sodium ethylmalonate, 3 - sodium succinate in $0.01 \mathrm{M}$ $\mathrm{NaCl}$ aqueous solution at room temperature under natural aeration. 


\section{Conclusions}

1. According to in situ ellipsometric measurements, the adsorption of sodium malonate, ethylmalonate, and succinate from a borate buffer with $\mathrm{pH} 7.4$ on oxidized copper surface at $E=0.0 \mathrm{~V}$ is adequately described by the full Temkin equation. The value of $\Delta G_{\mathrm{a} \text {, } \max }^{0}$ is higher for sodium succinate than for ethylmalonate and malonate $(77.4,69.4$ and $47.7 \mathrm{~kJ} / \mathrm{mol}$, respectively). These values indicate that chemisorption of anions on the surface occurs. This is due to the increased adsorption activity of ethylmalonate anions or an increase in the number of $\mathrm{CH}_{2}$ units in the succinate as compared to malonate anions.

2 . The advantage in the adsorption of ethylmalonate anions over malonate anions, although to a lesser extent, is also observed on reduced copper surface at $E=-0.60 \mathrm{~V}$ where $\Delta G_{\mathrm{a}, \max }^{0}==64.2$ and $38.3 \mathrm{~kJ} / \mathrm{mol}$. In both cases, these values are smaller than $\Delta G_{\mathrm{a}, \max }^{0}$ on oxidized copper, and the high values of the $f$ coefficients of reduced surface (1.90 and 2.62 for sodium ethylmalonate and malonate, respectively) as compared to the oxidized one (0.70 and 1.65) indicate a large energy inhomogeneity of the electrode surface at $E=$ $-0.60 \mathrm{~V}$. Since the value of $\Delta G_{\mathrm{a}, \max }^{0}$ for succinate is $53.1 \mathrm{~kJ} / \mathrm{mol}$, it can be assumed that at least succinate and ethylmalonate anions are chemisorbed on reduced copper surface.

3. Malonate, ethylmalonate and succinate anions, despite their high hydrophilicity, are capable of inhibiting the copper anodic dissolution in a borate buffer with $\mathrm{pH} 7.40$ containing $0.01 \mathrm{M} \mathrm{NaCl}$. At the same concentration of dicarboxylates $\left(C_{\mathrm{inh}}=3 \mathrm{mmol}\right)$, sodium ethylmalonate has the best protective effect, which, unlike malonate and succinate, does not increase the current density in the passive state of copper.

4. Sodium ethylmalonate and succinate proved to be advantageous over sodium malonate not only based the results of electrochemical studies and adsorption on copper surface. Corrosion tests of copper in an aqueous solution containing $0.01 \mathrm{M} \mathrm{NaCl}$ confirmed the best protective properties of ethylmalonate and sodium succinate. At $C_{\text {inh }}=3 \mathrm{mmol} / \mathrm{L}$, sodium ethylmalonate provides the highest degree of copper protection in a neutral chloride solution $(Z=91 \%)$.

\section{References}

1. Yu.I. Kuznetsov and L.P. Kazansky, Physicochemical aspects of metal protection by azoles, Russ. Chem. Rev., 2008, 77, no. 3, 219-232. doi: 10.1070/RC2008v077n03ABEH003753

2. I. Dugdale and J.B. Cotton, An electrochemical investigation on the prevention of staining of copper by benzotriazole, Corros. Sci., 1963, 3, no. 2. 69-74. doi: 10.1016/S0010-938X(63)80001-3

3. M.B. Petrović Mihajlović and M.M. Antonijević, Copper Corrosion Inhibitors. Period 2008-2014. A Review, Int. J. Electrochem. Sci., 2015, 10, 1027-1053. 
4. E. Abelev, D. Starosvetsky and Y. Ein-Eli, Potassium sorbate - A new aqueous copper corrosion inhibitor, Electrochim. Acta., 2007, 52, no. 5, 1975-1982. doi: 10.1016/j.electacta.2006.08.012

5. K. Devarayan, G. Mayakrishnan and N. Sulochana, Green Inhibitors for Corrosion of Metals: A Review, Chem. Sci. Rev. Lett., 2012, 1, no. 1, 1-8. Article CS10204205.

6. A.Yu. Tsyplenkova, Issledovanie vzaimodeistviya dikarbonovykh kislot s nekotorymi alifaticheskimi amidami (Study of the interaction of dicarboxylic acids with some aliphatic amides), Innovatsionnaya Nauka (Innovative Science), 2015, 4, no. 3, 18-20 (in Russian).

7. Yu.I. Kuznetsov, Organic corrosion inhibitors: where are we now? A review. Part II. Passivation and the role of chemical structure of carboxylates, Int. J. Corros. Scale Inhib., 2016, 5, no. 4. 282-318. doi: 10.17675/2305-6894-2016-5-4-1

8. E.G. Stroud and W.H.J. Vernon, The prevention of corrosion in packaging. III. Vapour phase inhibitors, J. Appl. Chem., 1952, 2, no. 4, 178-184. doi: $10.1002 /$ jctb.5010020403

9. G.T. Hefter, N.A. North and S.H. Tan, Organic corrosion inhibitors in neutral solutions; Part 1-Inhibition of steel, copper and aluminum by straight chain carboxylates, Corrosion, 1997, 53, 657-667. doi: 10.5006/1.3290298

10. A.S. Fouda and S. Habouba, Malonic Acid as Corrosion Inhibitor for Carbon Steel in $1 \mathrm{M}$ Hydrochloric Acid Solutions, J. Electrochem. Plat. Technol., 2015. doi: 10.12850/ISSN2196-0267.JEPT4982

11. U. Rammelt, S. Köehler and G. Reinhard, Electrochemical characterisation of the ability of dicarboxylic acid salts to the corrosion inhibition of mild steel in aqueous solutions, Corros. Sci., 2011, 53, no. 11, 3515-3520. doi: 10.1016/j.corsci.2011.06.023

12. D. Lahem, M. Poelman, F. Atmani and M.-G. Olivier, Synergistic improvement of inhibitive activity of dicarboxylates in preventing mild steel corrosion in neutral aqueous solution, Corros. Eng., Sci. Technol., 2012, 47, no. 6, 463-471. doi: 10.1179/1743278212Y.0000000030

13. R.M. Azzam and N.M. Bashara, Ellipsometry and Polarized Light, North-Holland, Amsterdam, 1977, 529.

14. M.O. Agafonkina, N.P. Andreeva, Yu.I. Kuznetsov and S.F. Timashev, Substituted Benzotriazoles as Inhibitors of Copper Corrosion in Borate Buffer Solutions, Russ. J. Phys. Chem. A, 2017, 91, no. 8, 1414-1421. doi: 10.1134/S0036024417080027

15. N.P. Andreeva, M.O. Agafonkina, I.A. Kuznetsov and Yu.I. Kuznetsov, Anodnye okisnye plenki na medi $\mathrm{v}$ neitral'nom boratnom bufernom rastvore i adsorbtsiya na nikh malonata natriya (Anodic copper oxide films in a neutral borate buffer solution and adsorption of sodium malonate on them), Korroz.: mater., zashch. (Corrosion: Materials, Protection), 2020, no. 10 (in print).

16. Yu.I. Kuznetsov, I.A. Kuznetsov and D.B. Vershok, Copper corrosion protection in neutral media by dicarboxylic acid salts, Int. J. Corros. Scale Inhib., 2019, 8, no. 4, 1022-1034. doi: $10.17675 / 2305-6894-2019-8-4-13$ 
17. N.P. Andreeva, M.O. Agafonkina and Yu.I. Kuznetsov, Osobennosti adsorbtsii karboksilatov na medi (Features of the carboxylates adsorption on copper), Institut fizicheskoi khimii i elektrokhimii im. A.N. Frumkina. 90 let. Sbornik nauchnykh trudov, 2019, 246-248 (in Russian). 